\title{
Un bel album de témoignages
}

\section{Jean Martin}

Dr méd., membre de la rédaction

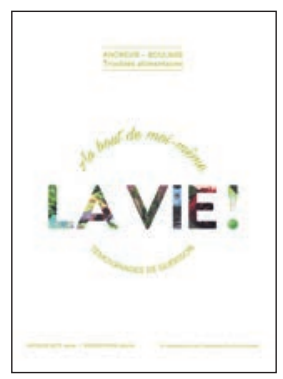

Association Boulimie Anorexie, av. de Villamont 19, 1005 Lausanne. Elle a fêté récemment ses 25 ans -j'ai eu le plaisir à l'époque, comme médecin cantonal, d'entretenir de bons contacts avec elle. 2 Ciao.ch - site d'information, d'aide et d'échanges pour les jeunes (Lausanne), créé il y a plus de vingt ans, très apprécié.

jean.martin[at]saez.ch
Nathalie Getz (textes), Vanessa Parisi (photos)

Au bout de moi-même LA VIE!

Anorexie-Boulimie - Troubles alimentaires

Sion, 2018.

107 pages. 30 CHF ( 25 CHF pour les membres

de $\mathrm{ABA})+$ frais de port

Il peut être directement commandé auprès d'ABA

à l'adresse info[at]boulimie-anorexie.ch

ISBN 978-2-8399-2406-1

Sensibilisée à la problématique des personnes souffrant de désordres alimentaires, la journaliste et thérapeute Nathalie Getz a développé le projet de donner la parole à des personnes qui en ont guéri. L'Association Boulimie Anorexie (ABA), à Lausanne ${ }^{1}$, y a vu un potentiel de «désavouer les croyances qu'il n'est possible de s'en sortir que grâce à la volonté ou jamais totalement». Suite à un appel à témoins de ABA, Nathalie Getz a rencontré neuf volontaires, puis a mis en forme leurs témoignages. A propos de ces répondants: de manière intéressante (à noter que l'échantillon n'a aucune prétention d'être représentatif), trois sont (devenus) thérapeutes et une psychologue. Les autres sont formatrice d'adultes, pasteure, juriste, architecte, ingénieure. Cinq ont entre 25 et 29 ans, trois ont 45 ans, une 61 ans. Sept femmes, deux hommes.

Emergence et reconnaissance de la maladie. «Je continuais à me faire vomir pour contrôler mon poids - avec une sensation de faire un truc interdit. Un engrenage installé plusieurs années dans le plus grand secret. Avec des comportements d'automutilation et des idées noires. C'est par hasard que ma famille a découvert ce que je vivais, par un mail que j'avais écrit à l'association $\mathrm{CIAO}^{2} »$ (Alice).

«Je n'ai jamais été dans le déni et lorsque le médecin a dit anorexie, j'ai rapidement accepté d'entreprendre une thérapie. Quelque chose n'allait pas, j'avais besoin d'aide.» Mots de Marie (45 ans) - qui ne s'appliquent pas à tous. «Ma médecin a très vite compris. Jamais elle n'a essayé de me culpabiliser ni demandé de faire un effort. Quand je lui ai dit 'tout ça, c'est plus fort que moi', elle a confirmé 'mais oui, c'est plus fort que vous!'."

Vécu de patient(e). On y trouve, comme cela est connu, des sentiments d'étrangeté, de honte, de manque d'estime de soi, des difficultés de contact social, des trou- bles obsessifs-compulsifs (besoin d'être parfait[e]), des idées suicidaires. Des hospitalisations en milieu somatique ou psychiatrique. Des périodes de mieux, puis des rechutes, pendant des années souvent.

«Le plus terrible, c'était ce sentiment de ne pas être vue. Les médecins ne voyaient que la maladie, l'anorexie» (Marie, 25 ans).

«'étais devenue dépendante de la balance. Je me souviens même être partie en randonnée en la prenant dans mon sac. [...] J'étais entourée de plein d'amis, mais la plupart ont fui» (Nadia).

«Le plus difficile, c'étaient les choix. Toutes les décisions étaient compliquées, car je n'avais plus le droit à l'erreur» (Christian).

Groupes de parole. «Nous avons contacté l'ABA qui propose des groupes de parole. Je redoutais d'y aller. Mais j'ai trouvé là un espace où il n'était pas nécessaire de cacher quoi que ce soit. Pour la première fois je me sentais acceptée et validée dans ma souffrance» (Alice). «Aux groupes de parole, des témoignages montraient qu'il était possible de guérir. [...] J’ai pu lâcher cette lutte permanente avec moi-même. J’ai commencé à être gentille avec moi, je reprenais confiance» (Nadia). Vers le mieux. "J'ai découvert alors une force en moi qui m'avait entraînée très bas, mais qui pouvait être engagée dans l'autre sens. C'est comme si je n'avais pas pu faire autrement que guérir.»

«Petit à petit, la vie a surpassé la maladie. Quand, je ne sais pas. Mais à un moment j'ai été certaine que la maladie était derrière moi. Même lorsque je me suis sentie fragilisée, elle n'est pas revenue. [...] Surtout, je sais qu'il m'est essentiel d'écouter et de respecter ce que je ressens, même si c'est douloureux" (Chloé).

Aujourd'hui. "Je me suis tellement maltraitée! Pendant dix ans, j'ai perdu du temps et fait souffrir des gens. J'essaie de me pardonner.»

«Si c'était à refaire, jamais je ne pourrais dire que je repasserais par là. Trop de souffrance!»

«L'essentiel, c'est d'apprendre à s'accorder de la bienveillance» (Christine).

En bref. Un livre susceptible d'être d'un grand profit aux patient(e)s comme à leurs proches, et à leurs soignants. Au delà de son intérêt par les histoires de vie racontées, $A u$ bout de moi-même LA VIE! est un bel ouvrage, très bien mis en page et bénéficiant des photos de Vanessa Parisi. 